\title{
The miR-17-92 MicroRNA Cluster Is Regulated by Multiple Mechanisms in B-Cell Malignancies
}

\author{
Ming Ji, ${ }^{* \dagger}$ Enyu Rao, ${ }^{\dagger \neq}$ \\ Himabindu Ramachandrareddy, ${ }^{\dagger}$ Yulei Shen, ${ }^{\dagger}$ \\ Chunsun Jiang, ${ }^{\dagger}$ Jianxiu Chen, ${ }^{*}$ Yiqiao $\mathrm{Hu},{ }^{*}$ \\ Angie Rizzino, ${ }^{\S}$ Wing C. Chan, ${ }^{\dagger}$ Kai Fu, ${ }^{\dagger}$ and \\ Timothy W. McKeithan?

\begin{abstract}
From the School of Life Science," Nanjing University, Nanjing, China; the Departments of Pathology and Microbiology, ${ }^{\dagger}$ and Internal Medicine," and the Eppley Institute for Research in Cancer and Allied Diseases, ${ }^{,}$University of Nebraska Medical Center, Omaha, Nebraska; and the Institute of Zoology, ${ }^{\ddagger}$ Chinese Academy of Sciences, Beijing, China
\end{abstract}

A cluster of six microRNAs (miRNAs), miR-17-92, is processed from the transcript of C13orf25, a gene amplified in some lymphomas and solid tumors. We find that levels of the miRNAs in the cluster do not vary entirely in parallel with each other or with the primary RNA in B-cell lines or normal cells, suggesting that processing or stability of the miRNAs is differentially regulated. Using luciferase reporter assays, we identified the region required for maximum promoter activity. Additional deletions and mutations indicated that the promoter is regulated by the collaborative activity of several transcription factors, most of which individually have only a moderate effect; mutation of a cluster of putative SP1-binding sites, however, reduces promoter activity by $70 \%$. MYC is known to regulate C13orf 25 ; surprisingly, mutation of a putative promoter MYCbinding site enhanced promoter activity. We found that the inhibitory MYC family member MXI1 bound to this region. The chromatin structure of a $>22.5-\mathrm{kb}$ region encompassing the gene contains peaks of activating histone marks, suggesting the presence of enhancers, and we confirmed that at least two regions have enhancer activity. Because the miR-17-92 cluster acts as an important oncogene in several cancers and targets genes important in regulating cell proliferation and survival, further studies of its transcriptional control are warranted. (Am J Pathol 2011, 179:1645-1656; DOI: 10.1016/j.ajpath.2011.06.008)
MicroRNAs (miRNAs) are single-stranded RNAs of 22 nucleotides that negatively regulate expression of their target genes posttranscriptionally. ${ }^{1-4}$ Various miRNAs are overexpressed or underexpressed in different types of cancer in humans and may function as either tumor suppressors or oncogenes. ${ }^{5-13}$ A cluster of six miRNAs (miR-17-92, comprising miR-17, miR18a, miR-20a, miR-19a, miR-19b-1, and miR-92a-1) is processed from the transcript of C13orf25 (also known as MIR17HG or MIRHG1), a gene amplified in some lymphomas and solid tumors ${ }^{5,14-17}$ and overexpressed in a large fraction of lymphomas. ${ }^{5}$ Overexpression of miR-17-92 accelerates lymphomagenesis in mouse models. ${ }^{5,8}$ The miRNAs in the cluster can target transcripts of genes, such as E2F1, PTEN, and BIM, which are important in cell proliferation and apoptosis. ${ }^{18-22}$ The transcriptional regulation of the miR-17-92 cluster, however, is poorly understood.

C13orf25 is activated by MYC and E2F transcription factors, and MYC was first shown to bind to a region containing a conserved CATGTG sequence in the first intron of the gene locus. ${ }^{8}$ By chromatin immunoprecipitation (ChIP) in HeLa cells, endogenous E2F1, E2F2, and E2F3 were found to directly bind the promoter of the gene and regulate its transcription. ${ }^{21}$ The primary transcript initiates from a consensus initiator sequence downstream of a nonconsensus TATA box. ${ }^{23}$ This TATA box is flanked by a TP53 binding site that medi-

Supported by University of Nebraska Medical Center Eppley Cancer Center pilot grants (T.W.M. and K.F.), a clinical investigator career development award from Lymphoma Research Foundation/Millennium Pharmaceuticals Inc. (K.F.), a National Cancer Institute grant (U01CA114778-03 to W.C.C.), and a National Institute of General Medical Sciences grant (GM-080751 to A.R.).

Accepted for publication June 17, 2011.

M.J. and E.R. contributed equally to this work

Supplemental material for this article can be found at http://ajp. amjpathol.org or at doi: 10.1016/j.ajpath.2011.06.008.

Address reprint requests to Kai Fu, M.D., Ph.D., Department of Pathology and Microbiology, University of Nebraska Medical Center, 983135 Nebraska Medical Center, Omaha, NE 68198; or Timothy W. McKeithan, Department of Internal Medicine, University of Nebraska Medical Center, 987680 Nebraska Medical Center, Omaha, NE 68198. E-mail: kfu@unmc.edu or tmckeith@ unmc.edu. 
ates repression under hypoxic conditions. ${ }^{24} \mathrm{~A}$ recent study showed a direct link between the action of IL-6 and the expression of C13orf25 mediated by STAT3. ${ }^{25}$

To explore transcriptional regulation of the mir17-92 cluster, we have begun to analyze the C13orf25 promoter and the first intron of the gene in several cell culture model systems. Because it is now clear that epigenetic mechanisms regulate miRNA expression, ${ }^{26-30}$ we also investigated histone posttranslational modifications (PTMs) in C13orf25 in normal B cells and in B-cell lines. Further studies of the transcriptional control of $C 13$ orf25 are warranted because the miR-17-92 cluster targets genes important in regulating cell proliferation and survival and acts as an important oncogene in several cancers, including lymphoma.

\section{Materials and Methods}

\section{Cell Lines and Normal B Cells}

Mantle cell lymphoma-derived cell lines (JeKo-1 and JVM2), Burkitt's lymphoma cell lines (CL-01, Daudi, Raji, and P3HR-1), a diffuse large B-cell lymphoma (DLBCL) cell line of germinal center B-cell type [SUDHL16 (hereafter, DHL16)], a mediastinal large B-cell lymphoma cell line (Karpas 1106), a Hodgkin's Iymphoma cell line (L428), and a myeloma cell line (U266) were maintained in RPMI 1640 medium (Invitrogen, Carlsbad, CA) supplemented with $10 \%$ fetal bovine serum and $1 \%$ penicillin/streptomycin (Invitrogen). A DLBCL line of germinal center B-cell type (DHL6) and two DLBCL lines of activated B-cell type (OCl-Ly3 and OCl-Ly10) were maintained in Iscove's modified Dulbecco's medium (Invitrogen) supplemented with 20\% human serum, $50 \mu \mathrm{mol} / \mathrm{L} 2$-mercaptoethanol, and $1 \%$ penicillin/streptomycin. HEK293T and NIH3T3 cells were maintained in Dulbecco's modified Eagle's medium (Invitrogen) supplemented with 10\% fetal bovine serum and $1 \%$ penicillin/streptomycin. HEK293T, NIH3T3, JeKo-1, JVM2, and U266 were obtained from American Type Culture Collection (Manassas, VA) and Karpas 1106 from Deutsche Sammlung von Mikroorganismen und Zellkulturen (Braunschweig, Germany). P3HR-1 and CL-01 were gifts from Dr. Luwen Zhang (University of Nebraska, Lincoln, NE) and Dr. Paolo Casali (University of California, Irvine, CA), respectively. All the other lines were a gift from Dr. Louis Staudt (National Cancer Institute, Bethesda, MD).

Primary cells isolated for miRNA studies, including naive $\mathrm{B}$ cells $\left(\mathrm{IgD}^{+}\right)$and centroblasts $\left(\mathrm{CD} 77^{+}\right)$, were isolated from tonsils using magnetic microbeads (Miltenyi Biotec Inc., Auburn, CA), as described. ${ }^{31}$

\section{miRNA Expression Levels}

miRNA expression profiling was conducted using the TaqMan human miRNA array set v2.0 (Applied Biosystems, Foster City, CA) with $300 \mathrm{ng}$ of total RNA from cell lines or normal cells. All the RNA samples were reverse transcribed using Megaplex RT primers (Invitrogen) for 40 cycles at $16^{\circ} \mathrm{C}$ for 2 minutes, $42^{\circ} \mathrm{C}$ for 1 minute, and $50^{\circ} \mathrm{C}$ for 1 second; were held at $85^{\circ} \mathrm{C}$ for 5 minutes to inactivate the reverse transcriptase; and were preamplified for 12 cycles using Megaplex PreAmp primers (Invitrogen). The diluted preamplified DNA was loaded onto the 384-well plate per the manufacturer's instructions, and real-time PCR was run using a 7900HT fast real-time PCR system (Applied Biosystems) in 384-well plates at $95^{\circ} \mathrm{C}$ for 10 minutes, followed by 40 cycles at $95^{\circ} \mathrm{C}$ for 15 seconds and $60^{\circ} \mathrm{C}$ for 1 minute. The $\mathrm{C}_{\mathrm{T}}$ is defined as the fractional cycle number at which the fluorescence exceeds the fixed threshold of 0.1 using $\mathrm{RQ}$ Manager 2.1 software (Applied Biosystems). Data from each 384-well plate were normalized with the average expression of $\mathrm{U} 6$ small nuclear RNA, the least variable control RNA analyzed on the plate. RNA was isolated using the RNeasy mini kit (Qiagen Inc., Valencia, CA), and miR-17-92 pri-miRNA and RPL13A mRNA, for normalization, were quantified by SYBR Green PCR (New England BioLabs, Inc., Ipswich, MA) using the DNA Engine Opticon 2 realtime PCR detection system (MJ Research, Waltham, MA) according to the manufacturer's instructions; the primers used are listed in Table 1. To determine the expression levels of mature miRNAs, TaqMan miRNA assays (Applied Biosystems) were performed using an Applied Biosystems $7900 \mathrm{HT}$ fast real-time PCR system and were normalized to U6 expression.

\section{Plasmids}

The firefly luciferase reporter vectors pGL3 basic, pGL3 promoter, and Renilla luciferase vectors pRL-SV40 are from Promega (Madison, WI). From BAC RP11-97P7 (BACPAC Resources Center, Children's Hospital Oakland Research Institute, Oakland, CA), a fragment containing the human C13orf25 promoter (-659 to $323 \mathrm{bp}$ ) was PCR amplified with the addition of an Xhol site at the $3^{\prime}$ end and was cloned into the pBLCAT7 plasmid. Four fragments of the promoter region were cut out from the human C13orf25pBLCAT7 plasmid by digestion with Xhol and either Pvull (P982; names correspond to the insert size in bp), Hpal (P606), Smal (P512), or Scal (P395) and were ligated into the Ecl136ll and Xhol sites of pGL3 basic vector. Additional $5^{\prime}$ deletions (P482 and P435) and 3' deletions (P339, P301, and P217) of P512 were generated by PCR. Downstream regions $A, B$, and $A B$ were $P C R$ amplified from $B A C D N A$ and then inserted into BamHI-Sall sites located downstream of the luciferase gene in the pGL3 C13orf25-P301 promoter or pGL3 promoter reporter vector. All the mutations were generated by the overlap PCR method from P512. Primers used in preparing these mutations and other constructs are listed in Table 1. The sequences of all the constructs prepared using PCR were confirmed by complete sequencing.

\section{Luciferase Reporter Assays}

HEK293T or NIH3T3 cells were plated at $5 \times 10^{4}$ cells per well in a 24-well plate 24 hours before transfection. The plasmids were cotransfected with pRL-SV40 using TurboFect transfection reagent (Fermentas, Hanover, MD) according to the manufacturer's instructions. DHL16 cells were transiently transfected using an Amaxa Nucleofector (Lonza, Basel, Switzerland) with cell line solution V combined with 
Table 1. Oligonucleotides Used in This Study

\begin{tabular}{|c|c|c|}
\hline Primer name & Sequence & Purpose \\
\hline miR-17 92-pri-F & $5^{\prime}$-CAGTAAAGGTAAGGAGAGCTCAATCTG-3' & RT-PCR \\
\hline miR-17 92-pri-R & 5'-CATACAACCACTAAGCTAAAGAATAATCTGA-3' & RT-PCR \\
\hline RPL13A-F & $5^{\prime}$-ACCGTCTCAAGGTGTTTGACG-3' & RT-PCR (normalization) \\
\hline RPL13A-R & $5^{\prime}$-GTACTTCCAGCCAACCTCGTG-3' & RT-PCR (normalization) \\
\hline ODC1-F & 5' -TGGGCGCTCTGAGGTGAGGG-3' & ChIP of ODC1 (positive control) \\
\hline ODC1-R & 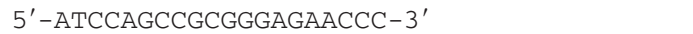 & ChIP of ODC1 (positive control) \\
\hline C13orf25-1-F & 5'-AAACGTTCTGAATGTTCTGGATTGT-3' & ChIP of site 1 \\
\hline C13orf25-1-R & 5'-CACAGCCTTCTCAAGTCAGCTAAA-3' & ChIP of site 1 \\
\hline C13orf25-2-F & $5^{\prime}$-AAGGAAGTATGAGCGAAACCCT-3' & ChIP of site 2 \\
\hline C13orf25-2-R & 5'-CAGGTTTCTTAGCAGGAGTTATTCA-3' & ChIP of site 2 \\
\hline C13orf25-3-F & $5^{\prime}$-GACTTGTACAATCACGAACCAGTG-3' & ChIP of site 3 \\
\hline C13orf25-3-R & 5'-TCTGGGTTCTCCAGTAGAAATAGC-3' & ChIP of site 3 \\
\hline C13orf25-4-F & 5'-TTTATGCTAATGAGGGAGTGG-3' & ChIP of site 4 \\
\hline C13orf25-4-R & $5^{\prime}$-GCTTTACTACGACCGGAGG-3' & ChIP of site 4 \\
\hline C13orf25-5-F & $5^{\prime}-$ GACGGCGAACACAATGGC- $3^{\prime}$ & ChIP of site 5 \\
\hline C13orf25-5-R & $5^{\prime}$-GCGTACAAAGTTTGGGGAACC - 3' & ChIP of site 5 \\
\hline C13orf25-6-F & $5^{\prime}$-AAGAATAGTCTGTGGGCTGCT-3' & ChIP of site 6 \\
\hline C13orf25-6-R & 5'-GCTATTTTCCAACCTCCTAACAGC-3' & ChIP of site 6 \\
\hline \multicolumn{3}{|c|}{ Cloning and deletions* } \\
\hline LucSeqR2 & 5'-CCAGGAACCAGGGCGTATC-3' & $\begin{array}{l}\text { Preparing promoter deletions and } \\
\text { mutations }\end{array}$ \\
\hline P482-F & $5^{\prime}$-atttggtaccGCTCCCGGCTCCCGCTCTC-3' & Preparing P482 deletion \\
\hline P435-F & $5^{\prime}$-atttggtacCGGGGCCTGCGGTGATTGG-3' & Preparing P435 deletion \\
\hline P512-F & $5^{\prime}$-ataggtaccgagGGGGAAGGCTG-3' & Preparing $3^{\prime}$ promoter deletions \\
\hline P339-R & $5^{\prime}$-gaaactcgagCCCGCGAGGAGAGCTTCG-3' & Preparing P339 deletion \\
\hline 301-R & 5'-caaactcgaGCGGCGCTGCGGTAGTCGTC-3' & Preparing P301 deletion \\
\hline 217-R & 5' - caaactcgagGGCACCTCGAAGGACCATG-3' & Preparing P217 deletion \\
\hline IntronA-F & $5^{\prime}$-gaaaggatcCCGGACGGCGAACACAATG-3' & Cloning "intron A" from BAC \\
\hline IntronA-R & $5^{\prime}$ - cattgtcgaCCTCCTTTGTGTCCCCCAG-3' & Cloning "intron A" from BAC \\
\hline IntronB-F & $5^{\prime}$ - caaaggatcC CTGGGGGACACAAAGGAG-3' & Cloning "intron B" from BAC \\
\hline IntronB-R & $5^{\prime}$-catagtcgac CTTTTACTCTCTAAGAAACCAATCC-3' & Cloning "intron B" from BAC \\
\hline \multicolumn{3}{|c|}{ Mutations by overlap } \\
\hline \multicolumn{3}{|c|}{$\mathrm{PCR}^{\dagger}$} \\
\hline P512-F2 & $5^{\prime}$-gtttttcgtacgaattcCCGGGGAAGGCTGC-3' & Preparing promoter mutations \\
\hline NFYmut-F & $5^{\prime}$ - GGCCTGCGGTGGCTAGCGGGCGGGCG-3' & Preparing promoter NFY mutation \\
\hline NFYmut-R & $5^{\prime}-$ CGCCCGCCCGC TAGCCACCGCAGGCC-3' & Preparing promoter NFY mutation \\
\hline SP1mut1-F & $5^{\prime}$-CGAGCCGCCGTTAACCGGGCCTGCGGTG-3' & Preparing promoter SP1 mutation 1 \\
\hline SP1mut1-R & 5'-CGAGCCGCCGTTAAC CGGGCCTGCGGTG-3' & Preparing promoter SP1 mutation 1 \\
\hline SP1mut2-F & $5^{\prime}$-GGTGATTGGCGAGAATTCGGGGAGGTCGG-3' & Preparing promoter SP1 mutation 2 \\
\hline SP1mut2-R & $5^{\prime}-$ CCGACCTCCCCGAATTC TCGCCAATCACC-3' & Preparing promoter SP1 mutation 2 \\
\hline ETSmut-F & 5' - GCGGGGAGGTCCGCGGTACTTTGTTTTTTATG-3' & Preparing promoter ETS mutation \\
\hline ETSmut-R & $5^{\prime}$ - CATAAAAAACAAAGTAC CGC GGACCTCCCCGC-3' & Preparing promoter ETS mutation \\
\hline OCTmut-F & $5^{\prime}$-CTTTGTTTTTTATCGATTTGAGGGAGTGGG $\mathrm{p}-3^{\prime}$ & Reparing promoter OCT mutation \\
\hline OCTmut-R & $5^{\prime}$ - CCCACTCCCTCAAATCGATAAAAAACAAAG-3' & Preparing promoter OCT mutation \\
\hline Ebox1mut-F & 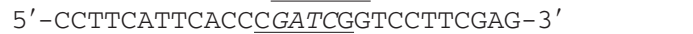 & Preparing promoter E-box mutation \\
\hline Ebox1mut-R & $5^{\prime}-$ CTCGAAGGACCGATCGGGTGAATGAAGG-3' & Preparing promoter E-box mutation \\
\hline E2Fmut1-F & $5^{\prime}$-CTGCGCCTTGGGCCCACTTCGCGCCCTCGGGCG-3' & Preparing promoter E2F mutation 1 \\
\hline E2Fmut1-R & $5^{\prime}$-CGCCCGAGGGCGCGAAGTGG GCCCAAGGCGCAG-3' & Preparing promoter E2F mutation 1 \\
\hline E2Fmut2-F & $5^{\prime}$-CGCCACTTCGGTACCTCGGGCGAG-3' & Preparing promoter E2F mutation 2 \\
\hline E2Fmut2-R & $5^{\prime}-$ CTCGCCCGAGGTACCGAAGTGGCG-3' & Preparing promoter E2F mutation 2 \\
\hline E2Fmut1,2-F & 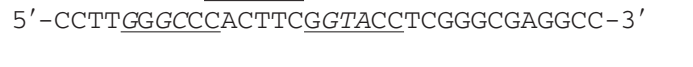 & $\begin{array}{l}\text { Preparing combined E2F mutations } \\
\quad 1 \& 2\end{array}$ \\
\hline E2Fmut1,2-R & $5^{\prime}-$ CGCCCGAGG TACCGAAGTGGGCCCAAGGCGCAG-3' & $\begin{array}{l}\text { Preparing combined E2F mutations } \\
\quad 1 \& 2\end{array}$ \\
\hline Ebox2mut-F & $5^{\prime}$-GCGGCGGCGGCGATCGGGGCAGGCCG-3' & Preparing intron E-box mutation 2 \\
\hline Ebox2mut-R & 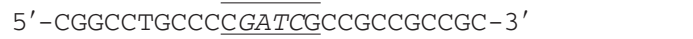 & Preparing intron E-box mutation 2 \\
\hline Ebox3mut-F & 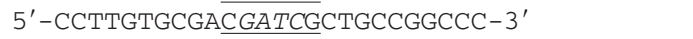 & Preparing intron E-box mutation 3 \\
\hline Ebox3mut-R & $5^{\prime}$ - GGGCCGGCAGCGATCGTCGCACAAGG-3' & Preparing intron E-box mutation 3 \\
\hline Ebox4mut-F & $5^{\prime}$ - CCAGTCATACGATCGGACCTAACTGC-3' & Preparing intron E-box mutation 4 \\
\hline Ebox4mut-R & $5^{\prime}$-GCAGTTAGGTCCGATCGTATGACTGG-3' & Preparing intron E-box mutation 4 \\
\hline
\end{tabular}

*In the "Cloning and deletions" section, added nucleotides are in lowercase and restriction sites are underlined.

†In the "Mutations by overlap PCR" section, altered nucleotides are in italics and new restriction sites are underlined.

program L-29. Luciferase assays were performed 24 hours after transfection using the Dual-Luciferase reporter assay system (Promega). Firefly luciferase activity was normalized to Renilla luciferase activity for each reaction. Triplicate transfected wells were analyzed for each group.

\section{ChIP}

ChIP assay was performed in P3HR-1 and DHL16 cells according to the protocol of the ChampionChIP one-day kit (SABiosciences Corp., Frederick, MD). The antibodies 

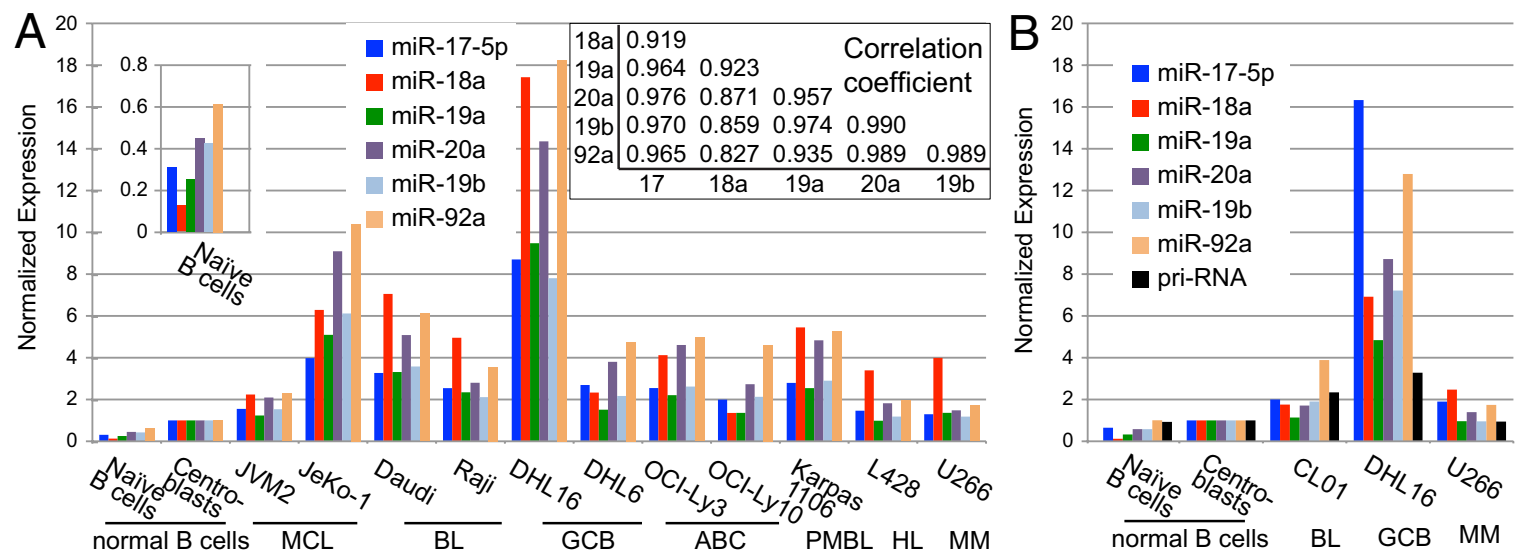

Figure 1. miRNA expression. A: Expression (linear scale) of the six miRNAs of the miR-17-92 cluster in normal naive human B cells and centroblasts and in 11 cell lines representative of various stages of mature B-cell differentiation analyzed in a PCR plate format and normalized to U6 RNA. Values are given as $2^{-\Delta \mathrm{C}_{\mathrm{T}}}$ Values of the centroblast samples were set to 1. The inset shows the correlation coefficients among the samples for each miRNA. B: Expression (linear scale) of the miR-17-92 cluster and of the primary RNA (pri-RNA), analyzed in individual PCR reactions in naive B cells and centroblasts, two of the cell lines analyzed in A, and a third cell line, CL01. Values of the centroblast samples were set to 1. ABC, activated B cell; BL, Burkitt's lymphoma; GCB, germinal center B cell; HL, Hodgkin's lymphoma; MCL, mantle cell lymphoma; MM, multiple myeloma; PMBL, primary mediastinal B cell lymphoma.

used in this study were purchased from Santa Cruz Biotechnology Inc. (Santa Cruz, CA): MYC (N-262, sc-764), MNT (M-132, sc-769), and MXI1 (G-16, sc-1042). Realtime PCR amplifications were performed using DyNAmo Capillary SYBR Green PCR master mix (New England BioLabs, Inc.) and the DNA Engine Opticon 2 real-time PCR detection system according to the manufacturer's instruction. Primer sequences are listed in Table 1.

\section{Labeling and Hybridization of ChIP Samples to a Custom Oligonucleotide Chip}

ChIP of modified histones and RNA polymerase II (pollI), amplification of ChIP DNA, and hybridization to a custom chip were performed as described previously. ${ }^{31}$ For analysis of histone modifications, we performed native ChIP on $20 \times 10^{6}$ cells without formaldehyde cross-linking. Nuclei were digested by micrococcal nuclease enzyme followed by mild sonication to obtain mononucleosomes. For analysis of polll binding, we performed ChIP after sonication after formaldehyde cross-linking to obtain DNA fragments ranging from 200 to $400 \mathrm{bp}$. Chromatin was then dialyzed into radioimmunoprecipitation assay buffer at $4^{\circ} \mathrm{C}$. We conjugated $4 \mu \mathrm{g}$ of H3-K9, K14-diacetyl-specific, and lysine-27 trimethylation-specific antibodies from Upstate Biotechnology (Millipore, Billerica, MA) (06-559 and 07-449) and lysine-4 monomethylation-specific, histone 3 lysine-4 trimethylation (H3K4me3)-specific, and polll-specific antibodies from Abcam Inc. (Cambridge, MA) (ab8895, ab8580, and ab5408) to Dynabeads protein A (Dynal Biotech, Oslo, Norway). We performed ChIP by overnight incubation of dialyzed chromatin with the antibody-loaded beads. We thoroughly washed the beads containing antibody and chromatin complexes, and the DNA was finally eluted from the beads. The eluted DNA was tested for enrichment by quantitative PCR. Input and enriched ChIP DNA were amplified by ligation-mediated PCR. Ligationmediated PCR-amplified input DNA and ChIP-enriched DNA were labeled with Cy3 and Cy5, respectively, and were hybridized to a custom $385 \mathrm{~K}$ array (Roche NimbleGen, Inc.,
Madison, $\mathrm{WI}$ ) by the NimbleGen service laboratory in Reykjavik, Iceland.

\section{Analysis of Publicly Available ChIP-Seq Data}

Coordinates for individual reads from genome-wide ChIP-Seq experiments in K562 and HeLa-S3 cells and DNase sensitivity analysis in K562 were downloaded (http://genome.ucsc.edu, last accessed July 27, 2010) and sorted; for each experimental replicate, the average fragment size was estimated using an Excel spreadsheet (Microsoft Corp., Redmond, WA) by determining the coordinate displacement that resulted in maximal overlap of forward and reverse reads in a continuous block of $\geq 200,000$ reads. Coordinates of forward and reverse reads in the C13orf25 region were adjusted based on these values, and the numbers of reads over all replicates and both orientations were combined and plotted in 20-bp increments using a 100-bp window. Evolutionary conservation in the C13orf25 promoter and close matches conserved consensus binding sites for transcription factors were determined using the Matlnspector program (Genomatix Software GmbH, Munich, Germany).

\section{Results}

\section{Expression of the miR-17-92 Cluster in B Cells}

miRNA expression profiling was initially conducted using the TaqMan human miRNA array. Because the miR-17-92 cluster is expressed in proliferating cells, we normalized the values to those of normal centroblasts, which proliferate rapidly. We observed decreased miR-17-92 expression in normal naive $B$ cells compared with that in centroblasts for each of the six miRNAs in the cluster but to varying extents, ranging from 1.28-fold in miR-92a to 7.8-fold in miR-18a (Figure 1A). Various tumor cell lines showed higher expression of the miRNA cluster than in 


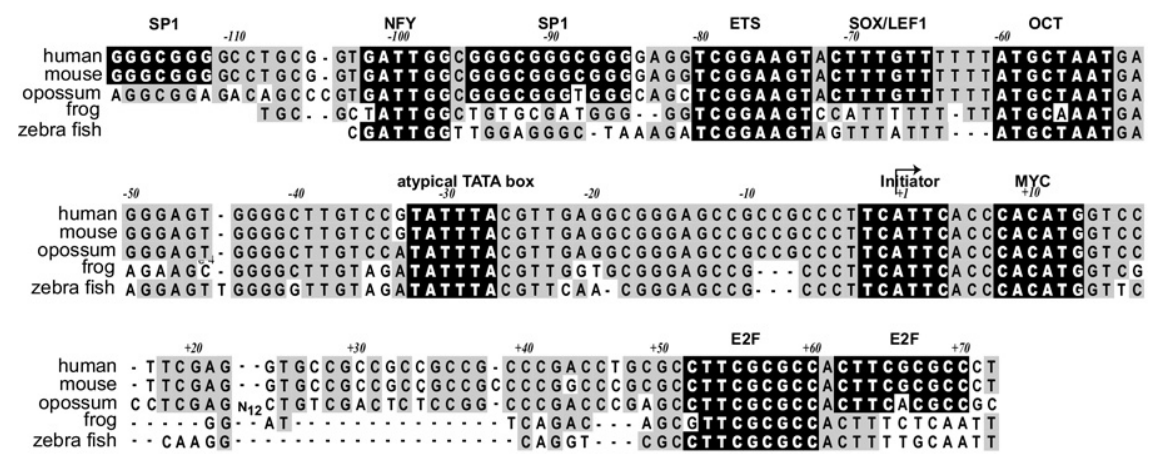

Figure 2. Promoter conservation. Alignment of sequences from human, mouse, opossum, frog, and zebra fish C13orf 25 orthologs using ClustalW, with further manual modifications to compact nonconserved regions. Strong matches to consensus transcription factor binding motifs are shown based on analysis using the Mat Inspector program normal centroblasts, with a ratio varying from 1.8 to 12.7 , averaging over the six miRNAs (Figure 1A). In general, there are strong correlations between the levels of the different miRNAs in the cluster in the 11 cell lines analyzed, representing different stages of B-cell differentiation. The miRNA whose level correlated least well with the others was miR-18a (Figure 1A and inset). Processing of this miRNA is known to be regulated by an RNA-binding protein $^{32}$; variation in efficiency of miR-18a processing among different cell lines is likely to be responsible for the relatively low correlation between miR-18a levels and those of the other members of the cluster.

Of the 11 cell lines, the greatest amounts of miR-17-92 expression were seen in JeKo-1 (a mantle cell lymphoma line) and in DHL16 (a DLBCL line of the germinal center B-cell subtype). Because JeKo-1 cells are known to have amplification of the C13orf25 locus, we wished to determine whether gene amplification was also responsible for the high-level miR-17-92 expression in DHL16 cells. This was done using two approaches. First, we performed quantitative PCR of genomic DNA with primers in C13orf25 and the control locus RPL13 in DHL16 and seven other lines. Four of the lines (DHL6, OCI-Ly1, OCI-Ly3, and JVM2) had virtually identical ratios of C13orf25 to RPL13, and it was assumed that they contain two copies of C13orf25. Relative to the average normalized quantity of C13orf25 DNA in these four lines, DHL16 showed a mean \pm SD ratio of $1.33 \pm 0.60$ and JeKo-1 a ratio of $5.8 \pm 1.6$ (see Supplemental Figure S1A at http://ajp.amjpathol.org). These data suggest that DHL16 has either two or three copies of C13orf25, whereas JeKo-1 has approximately 12. As a second approach to test for possible C13orf25 amplification in DHL16, we used the ChIP with hybridization to a custom oligonucleotide chip (ChIP-chip) data (described later herein) to estimate the relative copy numbers of the locus in DHL16 cells compared with those in normal centroblasts or naive B cells. We determined the ratio of the hybridization of input nucleosomal DNA to probes within C13orf25 to the hybridization to all the $>100$ genes on the custom array for the four histone modifications examined. The mean $\pm \mathrm{SD}$ ratio of DHL16 to normal centroblasts was $0.883 \pm 0.218$ and of DHL16 to naive B cells was $0.784 \pm 0.177$ (see Supplemental Figure S1B at http://ajp.amjpathol.org). Thus, gene amplification does not seem to be responsible for the increased expression of the miR-17-92 cluster in DHL16 cells.

Results of miRNA profiling were also confirmed by real-time RT-PCR amplification in at least triplicate for each of the miRNAs of the cluster in normal naive B cells, centroblasts, and three cell lines (Figure 1B). Because the levels of the miRNAs in the cluster did not vary completely in parallel, we also analyzed a dilution series to determine whether differences in PCR efficiency among the primer sets might be responsible for this variation; however, all the primer sets showed similar amplification efficiencies (data not shown).

\section{Elements Required for Full Promoter Activity Extend Approximately from -159 to 112 bp Relative to the Transcriptional Start Site}

miRNAs are first transcribed as primary miRNAs by poll.. ${ }^{33}$ As a preliminary indication of sequence elements that may be important in regulating the C13orf25 gene, we analyzed the degree of evolutionary conservation in the promoter region (Figure 2) and identified close matches to well-defined consensus binding sites for transcription factors. The region of highest conservation extends from approximately -118 to $70 \mathrm{bp}$ relative to the transcription start site (TSS). Within this region are numerous close matches to consensus transcription factor binding sites, most of which are conserved even in zebra fish. The promoter lies within a 1.9-kb CpG island [as defined at the UCSC Genome Bioinformatics website (http://genome.ucsc.edu, last accessed July $27,2010)]$, which, overall, has $63.5 \%$ guanine and cytosine content. As commonly found in promoters associated with CpG islands, several consensus sites for binding to the SP1 family are present. In addition to those noted in Figure 2, several close matches to SP1 consensus are found more proximal to the TSS. Despite being embedded in a CpG island, the promoter contains several AT-rich elements, including an octamer (OCT element), a possible LEF/SOX site, an atypical TATA box, and an initiator element. Other potentially important sites are described later herein. Additional highly conserved sequences likely represent binding sites for unidentified transcription factors.

We used transient transfection of promoter luciferase reporter constructs to identify the DNA elements important in regulating transcription. Although we are especially interested in transcription of the gene in B cells, miRNAs seem to be expressed in all proliferating cells; for example, miR17-92 miRNAs are expressed in a variety of mouse embry- 


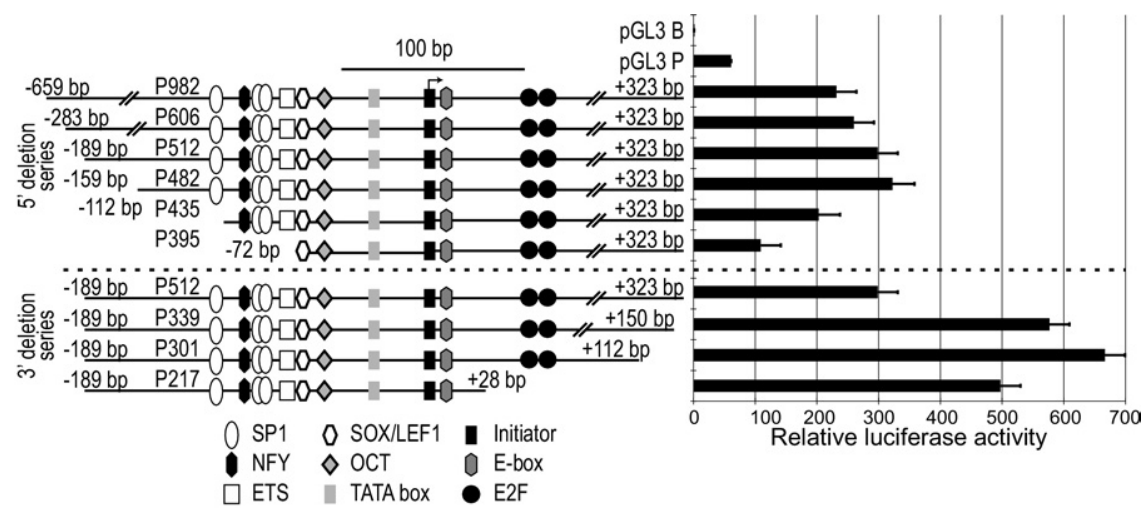

Figure 3. Firefly luciferase reporter assays in HEK293T cells of nested deletions of the C13orf 25 promoter region normalized to cotransfected $R e-$ nilla luciferase. Expression is relative to the promoterless pGL3 basic vector (pGL3 B), which was set to 1 . Results with the SV40 promoter (pGL3 P) are also shown. Diagrams at the left show the location of the motifs shown in Figure 2. Note that the results with P512 are shown twice for ease of comparison. Data are given as mean $\pm \mathrm{SD}$. onic tissues, ${ }^{34}$ and unlike most miRNAs tested, in situ hybridization showed them to be ubiquitously expressed in zebra fish embryos. ${ }^{35}$ The promoter contains consensus binding sites for many widely expressed transcription factors, suggesting that much of the regulation of the gene may be cell-type nonspecific. Thus, because B cells are notoriously difficult to transfect, detailed promoter analysis was performed in HEK293T cells.

To determine elements important for promoter activity, a nested 5' deletion series of six DNA fragments from the promoter region were cloned into the pGL3 basic luciferase reporter vector. Of these, initially four were prepared using convenient restriction enzyme sites (P982, P606, P512, and P395; names correspond to the length of promoter DNA included in the construct). In initial results (not shown), we determined that the P512 fragment, from -189 to $323 \mathrm{bp}$, had full activity in transient transfection experiments, whereas P395 had reduced activity. Based on these results, two additional constructs of size intermediate between P512 and P395 were generated by PCR cloning, and a small $5^{\prime}$ deletion of P512, removing 30 additional $5^{\prime} \mathrm{bp}$ (to $-159 \mathrm{bp}, \mathrm{P} 482$ ) was found to result in little change in activity (Figure 3 ). The similarity in activity of P982, P606, P512, and P482 shows that deleting less conserved regions from -659 to -159 bp does not reduce promoter activity, whereas a further 47-bp deletion (to $-112 \mathrm{bp}, \mathrm{P} 435$ ) reduced activity $\sim 37 \%$ compared with $\mathrm{P} 435$. Correlating these results with the affected putative transcription factor binding sites, the deletion in P435 resulted in loss of the most $5^{\prime}$ putative SP1 site, and deletion of the $5^{\prime}$ cluster of SP1 sites and the NFY and ETS sites in P395 reduced activity by $\sim 66 \%$ compared with P435.

A series of $3^{\prime}$ deletions was also analyzed (Figure 3). The P339 construct showed almost double the activity of the P512 construct. The P339 3' deletion removed poorly conserved regions that contain a potential initiation codon in a good Kozak context that is out of frame of the downstream luciferase gene. Thus, although we have not ruled out the possibility that the deleted region binds factors with repressor activity, the most likely reason for increased activity of these $3^{\prime}$ deletions is increased productive translation of the message. A further deletion (to $28 \mathrm{bp}$ ) that removed two consensus E2F sites (comparing P217 with P301) modestly decreased activity. These results imply that positive regulatory elements in the pro- moter extend approximately from -159 to $112 \mathrm{bp}$ from the transcriptional start site, encompassing the region of highest evolutionary conservation.

\section{The Promoter Is Regulated by the Collaborative Activity of Several Transcription Factors, Most of Which Individually Have Only a Moderate Effect}

To assess the importance of specific sequence elements in the region important for promoter activity, we prepared site-directed mutations. Mutations affecting all the SP1 sites reduced activity to $30 \%$, similar to deletion of the corresponding region. Mutations of individual SP1 sites and the NFY and OCT sites reduced activity by $\sim 40 \%$ to $50 \%$ each, whereas mutation of the putative ETS site did not affect the activity (Figure 4A).

Mutation of the first E2F site or of both E2F sites reduced activity by $\sim 25 \%$, similar to the effect of deleting the sites (comparing P217 with P301; Figure 3); mutation of the second E2F site alone had minimal effects. The promoter E-box is only one of several in the C13orf25 locus, and we refer to it as E1 in further analysis described later herein. Mutation of the E1 E-box increased activity by up to $\sim 40 \%$ (Figure $4 \mathrm{~A}$ ). Because C13orf25 is known to be regulated positively by MYC, this result was initially surprising. However, a variety of transcriptional repressors closely related to MYC, such as MNT and MXI1, are able to compete with it for heterodimerization with its partner MAX and to compete for binding to DNA. The effect of mutating the E-box suggests that C13orf25 is not only activated by MYC but also is inhibited by repressors of the MYC family. This repressive effect of the site predominates in HEK293T cells. ChIP data described later herein support this possibility.

These results of mutational analysis indicate that the promoter is regulated by the collaborative activity of several transcription factors, most of which individually have only a moderate effect. We further investigated the function of these sites by cotransfection of the P512 reporter construct with constructs expressing various transcription factors, namely, OCT2, SP1, ETS1, MYC, E2F1, and E2F3, and a dominant negative NFY vector (pNFYA29). ${ }^{36}$ The data indicated that only MYC and E2F1 expression vectors enhanced the activity (Figure 4B). 
A

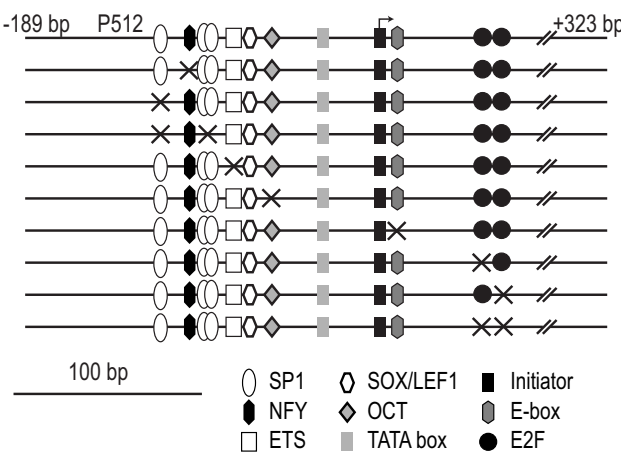

B

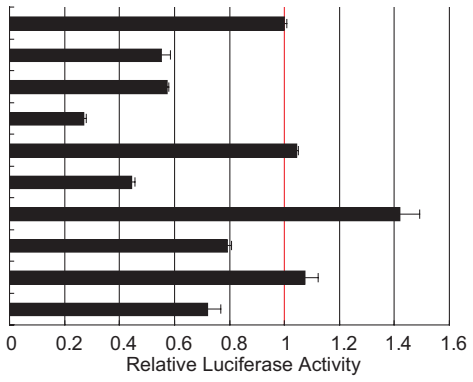

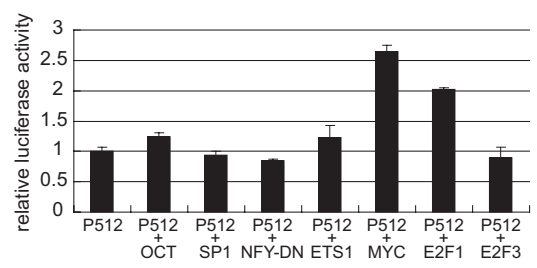

Figure 4. Multiple transcription factors control the C13orf 25 promoter. A: Luciferase reporter assays in HEK293T cells of various C13orf25 promoter-reporter constructs derived from plasmid P512 with mutations in transcription factor binding motifs, as shown in the diagrams at the left. B: Results in HEK293T cells of cotransfection of P512 with expression constructs for transcription factors as indicated. Data are given as mean \pm SD.

\section{Histone Modifications in the C13orf25 Locus}

As part of a larger analysis of $\sim 100$ genes important in $B$ cells, we analyzed histone PTMs in a 22.65-kb region using ChIP-chip. ${ }^{31}$ We analyzed the three B-cell lines for which miRNA abundances are shown in Figure $1 \mathrm{~B}$ and normal naive $B$ cells and centroblasts. Four PTMs were quantified: H3K4me3 and lysine-9 and -14 diacetylation (H3K9,14ac), associated with promoters and CpG islands; lysine-4 monomethylation, associated with enhancers or adjacent to regions of $\mathrm{H} 3 \mathrm{~K} 4 \mathrm{me} 3$; and lysine-27 trimethylation, associated with repression by polycomb complexes. In addition, for the three cell lines, we also analyzed binding of polll. To facilitate comparison among samples, data were globally normalized based on hybridization to the entire chip of 388,000 oligonucleotides.

The histone PTMs in the locus varied considerably among the samples (Figure 5). In the proximal portion of the gene, H3K4me3 varied the least, with peaks immediately $5^{\prime}$ and $3^{\prime}$ of the CpG island, a small peak near the TSS, and a peak $\sim 0.7 \mathrm{~kb}$ downstream of the TSS. In the three cell lines, H3K4me3 extends more $3^{\prime}$ and is found over the miRNA sequences. The location of $\mathrm{H} 3 \mathrm{~K} 9,14 \mathrm{ac}$ is similar but varies quantitatively, with very low values in naive $B$ cells and centroblasts but higher values in the cell lines. This analysis of the other genes in this array showed that the transcript level for a given gene correlated with the quantity of H3K9,14ac surrounding the promoter. ${ }^{31}$

A strong peak of polll binding was found near the TSS: polll was also found, to a variable extent, at the other sites of H3K4me3. Among the three cell line samples for which polll data were obtained, the most striking difference was the presence of polll over the miRNA sequences only in DHL16, which showed, by far, the highest levels of the mature miRNAs.

\section{Enhancers for the C13orf25 Locus}

Recently, specific histone PTMs have been identified as markers for distal enhancers. ${ }^{38}$ The presence of activating histone modifications in the C13orf25 gene body at considerable distances from the TSS raised the possibility that these are associated with regulatory regions, in

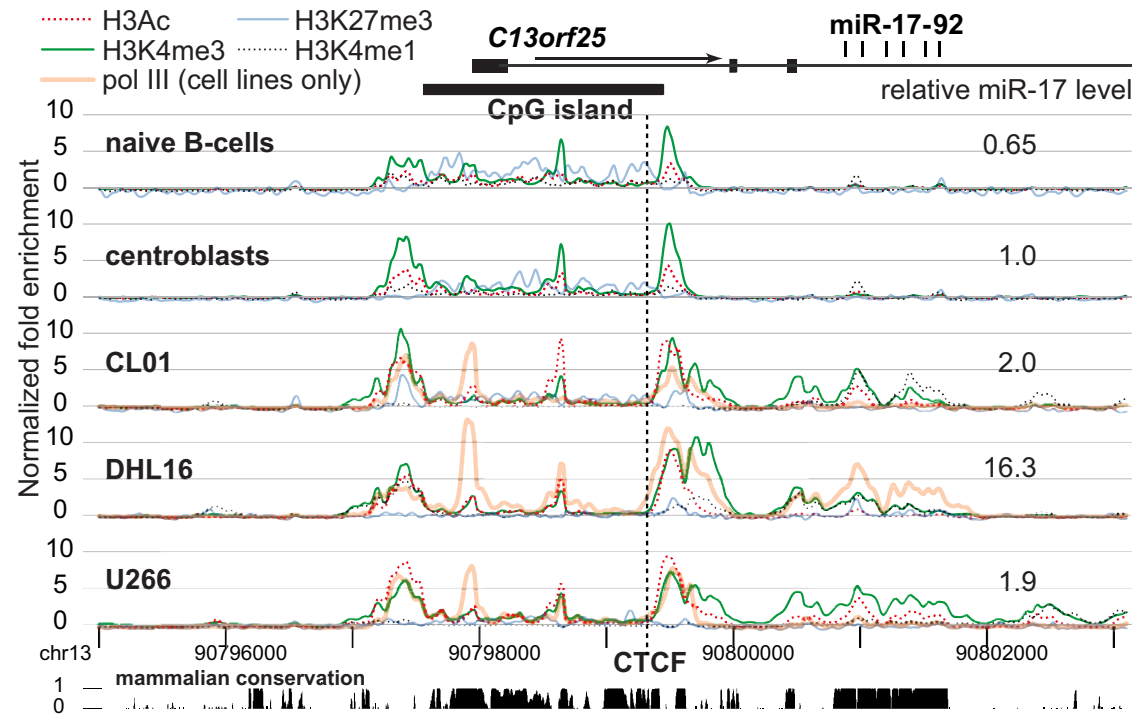

Figure 5. Chromatin structure. ChIP-chip results using a custom NimbleGen oligonucleotide array with the five samples analyzed in Figure $1 \mathrm{~B}$, namely, normal naive $\mathrm{B}$ cells and centroblasts and cell lines DHL16, CL01, and U266. The results from each hybridization experiment were globally normalized over the array, setting the enrichment of the top $0.1 \%$ of probes to 10 . At the top are shown the structure of the gene, the sequences encoding the mature miRNAs, and the extent of the $\mathrm{CpG}$ island encompassing the promoter. Expression of miR-17-5p (Figure 1B) is also shown. Sequence positions on chromosome 13 (chr13) are in hg18 coordinates. Conservation with 17 other placental mammals (from http://genome.ucsc.edu) is shown at the bottom of the figure; height indicates the relative Multiz ${ }^{37}$ conservation score (maximum is 1 ). Also shown is the position of a strong consensus site (5'-CGCCGCCCCCTGGCGGCTAC-3') for CCCTC-binding factor (CTCF), close to the peak maximum by ChIP-Seq in K562 (see Figure 7 ) and a variety of other cell lines. 


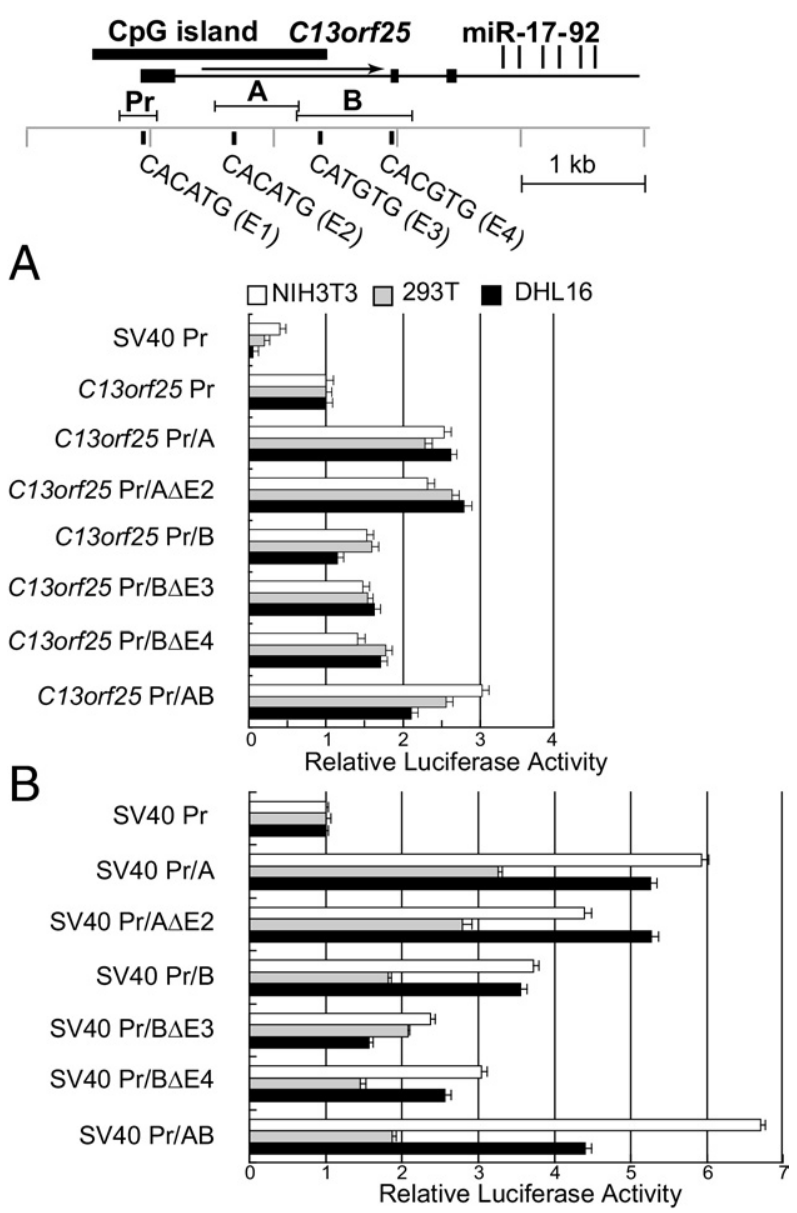

Figure 6. Potential C13orf25 enhancers. Luciferase activity in three cell lines (HEK293T, NIH3T3, and DHL16) of various constructs, some of which contain two regions, $\mathrm{A}$ and $\mathrm{B}$, being analyzed for enhancer activity. Where indicated, constructs containing point mutations were created in one or more putative E-boxes. The positions of the C13orf 25 promoter region ( $\mathrm{Pr}$ ) being analyzed, of regions $\mathrm{A}$ and $\mathrm{B}$, and of the four putative E-boxes are shown at the top. A: Results using constructs containing the C13orf 25 promoter. B: Results using constructs containing the SV40 promoter. Data are given as mean $\pm \mathrm{SD}$.

particular, enhancers. In an initial step to test this possibility, we analyzed two neighboring regions for enhancer activity: region $\mathrm{A}$ (586 to 1,265 bp) in intron 1, which encompasses a small peak of active histone modifications in the ChIP-chip data, and region B (1,248 to 2,183 $\mathrm{bp})$, extending into intron 2 , containing the largest peak of active histone modifications. The luciferase reporter pGL3 basic containing the C13orf25 promoter and region A displayed at least 2.3-fold greater luciferase activity than the control that contained only the promoter (Figure $6 \mathrm{~A}$ ). The plasmid C13orf25 promoter/region B showed modestly greater activity than the parental C13orf25 promoter construct in HEK293T, NIH3T3, and DHL16 cells but considerably less activity than the construct containing region $A$. There was no evidence of synergy when a construct containing both regions $\mathrm{A}$ and $\mathrm{B}$ was analyzed.

To confirm the enhancer activity of the intronic regions, we cloned them into the pGL3 promoter luciferase vector, in which luciferase expression is driven by the SV40 promoter. The pGL3 P/A luciferase construct showed more than fivefold luciferase activity compared with con- trol vector in DHL16 and NIH3T3 cells (Figure 6B). The pGL3 P/B vector showing 3.5-fold activity compared with control vector in the same two cell lines. Compared with pGL3 P/A and pGL3 P/B, pGL3 P/AB possessed the highest activity in NIH3T3 cells, whereas pGL3 P/A yielded the strongest luciferase activity in DHL16 and HEK293T cells.

\section{E-Box Motif Function in the C13orf25 Locus}

Because of the reported role of $\mathrm{MYC}$ in regulating C13orf25, we were especially interested in potential MYC binding sites. MYC and its family members normally bind DNA as heterodimers with a common partner, MAX. The highest affinity site for MAX homodimers and its heterodimers is CACGTG; only one such conserved site, in exon 2 ( $E 4$, region $B$ ), is found in or neighboring the region of active histone PTMs. Slightly lower affinity sites have the sequence CATGTG; three such sites are found in the region of active histone modification, including one site each in regions $A$ and $B$ (E2 and E3) and a site in the promoter region $(E 1)$, discussed previously herein, whose mutation led to an increase in promoter activity.

Mutations of E2, E3, and E4 were prepared in the C13orf25 promoter/A and C13orf25 promoter/B constructs and showed little effect (Figure 6A). Some of the same mutations in the SV40 promoter background (pGL3 $\mathrm{P} / \mathrm{A}$ and $\mathrm{pGL3} \mathrm{P} / \mathrm{B}$ ) reduced, but did not eliminate, enhancer activity (Figure 6B), with the effects varying among the cell lines tested. For DHL16, no effect was seen with the E2 mutation in region $A$, but mutation of E4 reduced enhancer activity in the $B$ region, whereas mutation of E3 strongly reduced enhancer activity.

\section{MXI1 Binds to the Promoter}

A previous study showed that the miR-17-92 cluster is directly transactivated by MYC, which directly binds to the first intron of $C 13$ orf $25 .{ }^{8}$ To identify the binding sites for MYC family members to the endogenous C13orf25 locus, we made use of publicly available genome-wide ChIP sequencing data (http://genome.ucsc.edu). ${ }^{39}$ Among the many cell lines analyzed, data for MAX and MYC binding are particularly extensive for HeLa-S3 and for the erythroleukemia cell line K562. For both lines and both transcription factors, by far the highest binding was at E3, followed by the promoter E1 (Figure 7, A and B). Binding at E2 was low, and at E4, it was almost undetectable. Two additional sites upstream of the promoter were found in both cell lines, centered approximately 610 and $300 \mathrm{bp}$ from the TSS. Within $50 \mathrm{bp}$ of each peak maximum was found the sequence CACGCG, with a single mismatch from the highest affinity site; a detailed analysis of MAX binding revealed that MAX binds detectably to such sites. ${ }^{40}$ Both of these sites are present in the construct P982 (Figure 3) but not in any of the smaller constructs; thus, these sites do not contribute obviously to reporter construct expression.

A possible explanation for the minimal MYC and MAX binding at E2 and E4 in K562 cells is chromatin inaccessibility. DNase I sensitivity is frequently used to identify 


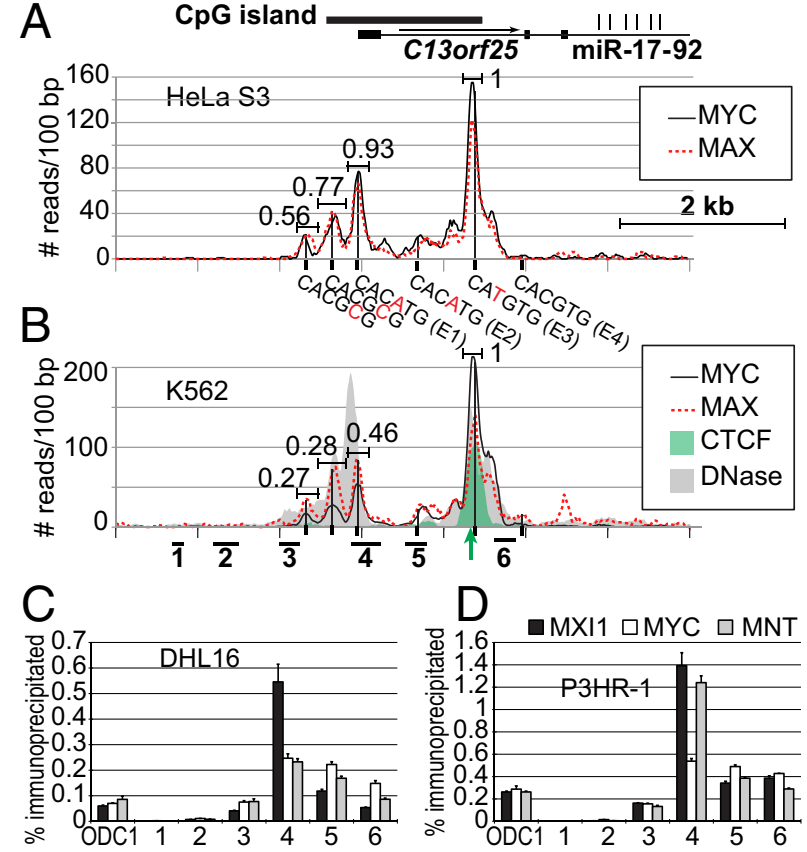

Figure 7. Binding of MYC family transcription factors. A: Genome-wide ChIP-Seq data in HeLa-S3 cells using antibodies that recognize MYC and MAX are shown. The positions of four putative E-boxes and of two E-box variants are also shown. The relative binding of MYC and MAX at various peaks was quantified, being normalized by setting the MYC/MAX ratio to 1 for E-box E3 B: Data for $\mathrm{K} 562$, as in A. Also shown are ChIP-Seq with antibodies to CCCTC-bindng factor (CTCF) and sites of DNase I cleavage ("digital" DNase hypersensitivity analysis; sequencing reads prepared by the Stamatoyannopoulos Laboratory at the University of Washington were downloaded from http://genome.ucsc.edu). The arrow shows the position of a close match to the consensus CTCF DNA-binding sequence. The positions of the PCR products analyzed by conventional ChIP in DHL16 (C) and P3HR-1 (D) are shown at the bottom. C: Results of ChIP and quantitative real-time PCR with probes across the C13orf25 locus in DHL16 cells using antibodies that recognize MYC, MXI1, and MNT. D: As in C, analyzing ChIP in P2HR-1 cells. Note that E1 and E2 lie within the amplicons of primer sets 4 and 5, respectively, whereas the primer set 6 amplicon lies between $\mathrm{E} 3$ and $\mathrm{E} 4$.

accessible DNA, as found at enhancers, promoters, and other regulatory regions. Publicly available genome-wide DNase sensitivity for the K562 cell line (http://genome. ucsc.edu, last accessed July 27, 2010) revealed that the sequences surrounding E2 and E4 were insensitive to DNase digestion (Figure 7B), consistent with the hypothesis that a closed chromatin conformation blocks MYC and MAX binding to these sites.

Although in HeLa the relative binding of MYC and MAX was similar at E1 and E3, in K562, considerably lower relative binding of $M Y C$ was found at E1 than at E3, suggesting that at least half of the MAX bound to E1 was in heterodimers with proteins other than MYC and that different E-boxes preferentially bind different MYC family members. If so, this would provide a potential explanation for the paradoxical increase in luciferase activity on mutating $\mathrm{E} 1$ and the different effects of mutating the other E-boxes (Figures 4 and 6).

The results in K562 suggested that family members in addition to MYC may bind to E1 at the promoter. To test this possibility, we performed ChIP with antibodies to MYC and to two MYC family members, MNT and MXI1, which bind to E-boxes as heterodimers with MAX to function as dedicated transcriptional repressors. ${ }^{41}$ Isolated
DNA was analyzed by quantitative real-time PCR using several probes across the C13orf25 locus and in the promoter of the known MYC target ODC1. Two cell lines were used for ChIP: DHL16 and, for comparison, another B-cell line, the Burkitt's lymphoma cell line P3HR-1, which expresses high levels of MYC. The immunoprecipitated DNA was enriched at the promoter and intronic regions for all three antibodies, with highest enrichment at the promoter (Figure 7C). The relative enrichment of MYC, MXI1, and MNT, however, varied at the various sites, with greater enrichment of MXI1 and, in P3HR-1, of MNT at the promoter than at intronic sites. This is consistent with the ChIP-seq data available for K562 and for the increased activity of the C13orf25 promoter when the E1 E-box is disrupted (Figure 4A).

\section{Discussion}

C13orf25, containing the miR-17-92 cluster, is amplified in some lymphomas, but the miRNAs themselves are much more frequently overexpressed in Iymphoma. ${ }^{5}$ In the cell lines we analyzed, overexpression was particularly striking in the case of DHL16, in which the locus is not amplified. These data suggest that abundance of the miRNAs in the miR-17-92 cluster is regulated at several levels. Although this analysis was centered on transcriptional regulation, the results suggest that differential processing or stability of the miRNAs also influences their abundance. The abundance of the six miRNAs correlate relatively well except for miR-18a, whose processing has been shown to be regulated by binding of hnRNPA 1 to its conserved terminal loop. ${ }^{32,42}$ In particular, the abundance of miR-18a is strikingly low in naive B cells. A study of miR-17-92 during mouse development also showed that expression of the individual miRNAs of the cluster did not vary entirely in parallel, ${ }^{34}$ with miR-18a showing a disproportionate decrease in several postnatal tissues compared with the embryo. In addition to the variation among the miRNAs in the cluster, the overall degree of processing is likely to vary because the levels of the primary RNA do not correlate well with the levels of the mature miRNAs. This is especially striking in the case of DHL16, in which the primary RNA levels are 3.3-fold those of normal centroblasts, whereas the ratios for the mature miRNAs vary from 4.8 to 12.8 .

These results suggest that the primary RNA is processed more efficiently in DHL16 than in the other cell lines and normal samples. Because processing requires cleavage of the primary RNA, more efficient processing would be expected to result in lower steady-state levels of the primary RNA. Thus, the modestly enhanced levels of primary RNA in DHL16 cells may not fully reflect the rate of transcription in this cell line. The most striking difference in ChIP-chip results between DHL16 and the other two lines that were analyzed is the presence of polll over the miRNA sequences in DHL16 only. An intriguing possibility is that the presence of polll over the miRNAencoding sequences is due to slowing of transcriptional elongation through the region by unknown mechanisms, 
allowing for proper folding of the RNA hairpins and subsequent cleavage by the Drosha complex.

The present analysis of vertebrate sequence conservation revealed that the promoter region comprises several putative SP1 sites; sites for NFY, ETS, OCT, and MYC; and two tandem E2F sites. This region is highly conserved in vertebrates, and most of the putative transcription factor binding sites are conserved even in fish. Additional highly conserved sequences likely represent binding sites for unidentified transcription factors.

Several early studies demonstrated that the E2F family of transcription factors can directly bind C13orf25 and stimulate its transcription. ${ }^{21,23}$ The present studies indicated that a $3^{\prime}$ deletion, eliminating the second E2F site, reduced activity by $\sim 30 \%$, whereas mutation of both sites reduced activity to a similar extent. The mutation of putative SP1 sites reduced activity of promoter-reporter constructs by $70 \%$, suggesting that the SP/KLF family of transcription factors may be important in regulating this gene. To investigate the role of SP1 in the transcription of this gene, SP1 expression vectors were cotransfected with the promoter reporter. The failure to affect transcription is likely because SP1 is abundantly and ubiquitously expressed and cotransfection with its expression vector did not sufficiently perturb the overall level of the protein to affect transcription.

From ChIP-chip analysis of SP1 binding to chromosomes 21 and 22, a minimal estimate of the number of SP1-binding sites in the human genome was $12,000 .{ }^{43}$ Initially, SP1 was thought to have no role other than to constitutively activate housekeeping genes, but evidence has mounted for important roles in cell proliferation and tumorigenesis. ${ }^{44}$ Additional specificity is likely provided by its direct interaction with numerous other transcription factors, including several that may affect C13orf25 expression, including E2F1, OCT1, NFYA, and NFYC. Interactions with E2F2 and E2F3, ETS1, and MYC have also been identified, but these may be indirect. ${ }^{44}$ Thus, the SP1 sites may be important in promoting cooperative recruitment of SP1 along with other transcription factors that bind the promoter.

Histone modifications are now known to play a central role in the regulation of gene transcription. ${ }^{45-47}$ We performed ChIP-chip to identify the histone modifications associated with the C13orf25 locus in normal B cells and in various B-cell lines. The various samples showed considerable variation in the pattern of histone PTMs. One of the most striking differences was the very low level of H3K9,14ac in naive B cells and normal centroblasts compared with in the three cell lines. H3K9,14ac has been shown to be important in recruiting the general transcription factor complex TFIID to promoters. ${ }^{48}$ In addition, the observation downstream of the promoter of histone PTMs associated with active transcription suggested the presence of intronic enhancers, which we confirmed using reporter assays.

Previous studies in a Burkitt's cell line with regulated MYC expression demonstrated that the C13orf 25 locus is directly transactivated by MYC and that MYC directly binds to the first intron. ${ }^{8}$ Resting naive $\mathrm{B}$ cells have among the highest levels of MYC MRNA among undivid- ing cells (http://biogps.gnf.org, last accessed July 27, 2010). Surprisingly, in contrast to other dividing cells, normal rapidly dividing centroblasts have less MYC mRNA than resting B cells, and MYC protein is undetectable by immunohistochemical analysis in normal centroblasts. ${ }^{49}$ In contrast, MYC mRNA is up-regulated in dividing $B$-lineage cells at other differentiation stages and in $\mathrm{B}$ cells induced to divide by mitogens in vitro. ${ }^{50}$ This unusual regulation of MYC in centroblasts seems to be abrogated in most DLBCLs. ${ }^{51}$ In normal centroblasts, the low level of MYC protein may contribute to the low level of the activating histone PTM H3K9,14ac found in the C13orf25 locus (Figure 5) and the minimal up-regulation of miR-17-92 expression (Figure 1).

After identifying several conserved E-boxes in the C13orf25 locus that function in transient transfection experiments, we examined which of the putative E-boxes can bind MYC family members in their normal chromosomal context. Publicly available ChIP-seq data allow the sites of binding to be defined more precisely (Figure 7). It is likely that the considerable differences in HeLa and K562 cells in MYC and MAX binding among the four conserved E-boxes result, in part, from differences in chromatin accessibility and structure. E2 and E4 are in regions of low DNase sensitivity in K562, suggesting that these regions are poorly accessible to transcription factor binding. In contrast, E1 and E3 lie in regions of DNase hypersensitivity in K562 (Figure 7B), the first corresponding to the promoter and the second lying only $36 \mathrm{bp}$ from a binding site for CCCTC-binding factor, which is efficient in excluding nucleosomes and positioning neighboring nucleosomes ${ }^{52}$ and, thus, would be expected to contribute to binding at the neighboring E3 site. CCCTC-binding factor has complex effects on transcription but functions in part by promoting chromatin looping ${ }^{53}$; thus, it may contribute to interaction of the neighboring intronic enhancers with the promoter. MYC binding is also associated with areas of $\mathrm{H} 3 \mathrm{~K} 4 \mathrm{me} 3$ and $\mathrm{H} 3$ acetylation. ${ }^{54}$ The ChIP-chip experiments (Figure 5) revealed prominent peaks of H3K4me3 and H3K9,14ac in the three cell lines analyzed immediately neighboring E1 and E3. Peaks of these histone PTMs, albeit smaller, were also detected adjacent to E2. The active histone PTMs are consistent with the ChIP data with MYC family members (Figure 7C), which showed relatively high enrichment with primer pair 5, whose amplicon includes E2. Although mutation of E2 did not affect luciferase activity in DHL16 in transient transfection experiments (Figure 6), these data raise the possibility that E2 is active in B cells in its normal chromosomal context, in contrast to K562 and HeLa S3.

Analysis of high-quality ChIP-seq data on MYC and MAX binding in K562 and HeLa S3 cells showed that binding to the two factors did not occur entirely in parallel across the C13orf25 locus (Figure 7, A and B); in particular, compared with binding at E3, proportionally less MYC binding was found at the promoter (E1) in K562, but little difference was found in HeLa S3 cells. The differential binding at E1 and E3 in K562, despite their identical core sequences, may be due to differences in flanking sequences, to differences in histone modifications, or to binding by cooperating transcription factors. We also 
found preferential binding of inhibitory MYC family members to the promoter (E1) in B-cell lines (Figure 7C). Preferential binding of inhibitory MYC family members to E1 may explain why mutation of E1 increased promoterreporter activity (Figure $4 \mathrm{~A}$ ).

Binding to two noncanonical E-boxes (CACGCG) upstream of the promoter showed a large relative excess of MAX binding over MYC binding (Figure 7). MAX has been shown to bind to this sequence ${ }^{40}$ with an affinity that is appreciable although lower than to canonical sites, and MYC can activate transcription of TAF4B through such a site. ${ }^{55}$ MNT, however, has been reported to bind with higher affinity to this noncanonical sequence than to canonical E-boxes. ${ }^{56}$ Thus, it is likely that in some cell types these upstream noncanonical sites are preferentially bound by MNT and perhaps other repressive MYC family members whose sequence specificity has not been analyzed in detail. Although deleting these sequences had little effect in the promoter-reporter assays (Figure 4A), we cannot exclude the possibility that they are functional in their normal chromosomal context.

In summary, we provide evidence that the abundance of C13orf25 miRNAs is affected not only by transcriptional mechanisms but likely also by varying processing efficiency. We mapped the promoter and identified intronic regions with enhancer activity. Finally, these data suggest that $C 13$ orf25 is bound not only by MYC but also by inhibitory members of the MYC family, allowing for a complex mode of regulation by MYC family proteins.

\section{Acknowledgments}

We thank Drs. Javeed Iqbal for gene expression analysis, Zhong Feng Liu for technical assistance with gene expression analysis, and Brian Boer for initial subcloning of the C13orf25 promoter region.

\section{References}

1. Ambros V: The functions of animal microRNAs. Nature 2004, 431: 350-355

2. Bartel DP: MicroRNAs: genomics, biogenesis, mechanism, and function. Cell 2004, 116:281-297

3. He L, Hannon GJ: MicroRNAs: small RNAs with a big role in gene regulation. Nat Rev Genet 2004, 5:522-531

4. Zamore PD, Haley B: Ribo-gnome: the big world of small RNAs. Science 2005, 309:1519-1524

5. He L, Thomson JM, Hemann MT, Hernando-Monge E, Mu D, Goodson S, Powers S, Cordon-Cardo C, Lowe SW, Hannon GJ, Hammond SM: A microRNA polycistron as a potential human oncogene. Nature 2005, 435:828-833

6. Kim H, Huang W, Jiang X, Pennicooke B, Park PJ, Johnson MD: Integrative genome analysis reveals an oncomir/oncogene cluster regulating glioblastoma survivorship. Proc Natl Acad Sci U S A 2010, 107:2183-2188

7. Johnson SM, Grosshans H, Shingara J, Byrom M, Jarvis R, Cheng A, Labourier E, Reinert KL, Brown D, Slack FJ: RAS is regulated by the let-7 microRNA family. Cell 2005, 120:635-647

8. O'Donnell KA, Wentzel EA, Zeller KI, Dang CV, Mendell JT: c-Mycregulated microRNAs modulate E2F1 expression. Nature 2005, 435: 839-843

9. Costinean S, Zanesi N, Pekarsky Y, Tili E, Volinia S, Heerema N, Croce CM: Pre-B cell proliferation and lymphoblastic leukemia/high-grade lymphoma in $\mathrm{E}(\mathrm{mu})-\mathrm{miR} 155$ transgenic mice. Proc Natl Acad Sci U S A 2006, 103:7024-7029

10. Voorhoeve PM, le Sage C, Schrier M, Gillis AJ, Stoop H, Nagel R, Liu YP, van Duijse J, Drost J, Griekspoor A, Zlotorynski E, Yabuta N, De Vita G, Nojima H, Looijenga LH, Agami R: A genetic screen implicates miRNA-372 and miRNA-373 as oncogenes in testicular germ cell tumors. Cell 2006, 124:1169-1181

11. He L, He X, Lim LP, de Stanchina E, Xuan Z, Liang Y, Xue W, Zender L, Magnus J, Ridzon D, Jackson AL, Linsley PS, Chen C, Lowe SW, Cleary MA, Hannon GJ: A microRNA component of the p53 tumour suppressor network. Nature 2007, 447:1130-1134

12. Mestdagh $P$, Fredlund E, Pattyn F, Schulte JH, Muth D, Vermeulen J, Kumps C, Schlierf S, De Preter K, Van Roy N, Noguera R, Laureys G, Schramm A, Eggert A, Westermann F, Speleman F, Vandesompele J: MYCN/C-MYC-induced microRNAs repress coding gene networks associated with poor outcome in MYCN/c-MYC-activated tumors. Oncogene 2010, 29:1394-1404

13. Trang P, Medina PP, Wiggins JF, Ruffino L, Kelnar K, Omotola M, Homer R, Brown D, Bader AG, Weidhaas JB, Slack FJ: Regression of murine lung tumors by the let-7 microRNA. Oncogene 2010, 29: 1580-1587

14. Ota A, Tagawa H, Karnan S, Tsuzuki S, Karpas A, Kira S, Yoshida Y, Seto M: Identification and characterization of a novel gene, C13orf25, as a target for 13q31-q32 amplification in malignant lymphoma. Cancer Res 2004, 64:3087-3095

15. Hayashita $Y$, Osada $H$, Tatematsu $Y$, Yamada $H$, Yanagisawa $K$, Tomida S, Yatabe Y, Kawahara K, Sekido Y, Takahashi T: A polycistronic microRNA cluster, miR-17-92, is overexpressed in human lung cancers and enhances cell proliferation. Cancer Res 2005, 65:96289632

16. Tagawa $H$, Seto $M$ : A microRNA cluster as a target of genomic amplification in malignant lymphoma. Leukemia 2005, 19:2013-2016

17. Rinaldi A, Poretti G, Kwee I, Zucca E, Catapano CV, Tibiletti MG, Bertoni F: Concomitant MYC and microRNA cluster miR-17-92 (C13orf25) amplification in human mantle cell lymphoma. Leuk Lymphoma 2007, 48:410-412

18. Koralov SB, Muljo SA, Galler GR, Krek A, Chakraborty T, Kanellopoulou C, Jensen K, Cobb BS, Merkenschlager M, Rajewsky N, Rajewsky $\mathrm{K}$ : Dicer ablation affects antibody diversity and cell survival in the $\mathrm{B}$ lymphocyte lineage. Cell 2008, 132:860-874

19. Ventura A, Young AG, Winslow MM, Lintault L, Meissner A, Erkeland SJ, Newman J, Bronson RT, Crowley D, Stone JR, Jaenisch R, Sharp PA, Jacks T: Targeted deletion reveals essential and overlapping functions of the miR-17 92 family of miRNA clusters. Cell 2008, 132:875-886

20. Xiao C, Srinivasan L, Calado DP, Patterson HC, Zhang B, Wang J, Henderson JM, Kutok JL, Rajewsky K: Lymphoproliferative disease and autoimmunity in mice with increased miR-17-92 expression in lymphocytes. Nat Immunol 2008, 9:405-414

21. Sylvestre Y, De Guire V, Querido E, Mukhopadhyay UK, Bourdeau V, Major F, Ferbeyre G, Chartrand P: An E2F/miR-20a autoregulatory feedback loop. J Biol Chem 2007, 282:2135-2143

22. Pickering MT, Stadler BM, Kowalik TF: miR-17 and miR-20a temper an E2F1-induced G1 checkpoint to regulate cell cycle progression. Oncogene 2009, 28:140-145

23. Woods K, Thomson JM, Hammond SM: Direct regulation of an oncogenic micro-RNA cluster by E2F transcription factors. J Biol Chem 2007, 282:2130-2134

24. Yan HL, Xue G, Mei Q, Wang YZ, Ding FX, Liu MF, Lu MH, Tang Y, Yu HY, Sun SH: Repression of the miR-17-92 cluster by p53 has an important function in hypoxia-induced apoptosis. EMBO J 2009, 28: 2719-2732

25. Brock M, Trenkmann M, Gay RE, Michel BA, Gay S, Fischler M, Ulrich S, Speich R, Huber LC: Interleukin-6 modulates the expression of the bone morphogenic protein receptor type II through a novel STAT3microRNA cluster 17/92 pathway. Circ Res 2009, 104:1184-1191

26. Huang YW, Liu JC, Deatherage DE, Luo J, Mutch DG, Goodfellow PJ, Miller DS, Huang TH: Epigenetic repression of microRNA-129-2 leads to overexpression of SOX4 oncogene in endometrial cancer. Cancer Res 2009, 69:9038-9046

27. Roman-Gomez J, Agirre X, Jimenez-Velasco A, Arqueros V, VilasZornoza A, Rodriguez-Otero P, Martin-Subero I, Garate L, Cordeu L, San Jose-Eneriz E, Martin V, Castillejo JA, Bandres E, Calasanz MJ, Siebert R, Heiniger A, Torres A, Prosper F: Epigenetic regulation of 
microRNAs in acute lymphoblastic leukemia. J Clin Oncol 2009, 27:1316-1322

28. Tsai KW, Kao HW, Chen HC, Chen SJ, Lin WC: Epigenetic control of the expression of a primate-specific microRNA cluster in human cancer cells. Epigenetics 2009, 4:587-592

29. Saetrom P, Snove O Jr, Rossi JJ: Epigenetics and microRNAs. Pediatr Res 2007, 61:17R-23R

30. Saito Y, Jones PA: Epigenetic activation of tumor suppressor microRNAs in human cancer cells. Cell Cycle 2006, 5:2220-2222

31. Ramachandrareddy H, Bouska A, Shen Y, Ji M, Rizzino A, Chan WC, McKeithan TW: BCL6 promoter interacts with far upstream sequences with greatly enhanced activating histone modifications in germinal center B cells. Proc Natl Acad Sci U S A 2010, 107:1193011935

32. Michlewski G, Guil S, Semple CA, Caceres JF: Posttranscriptional regulation of miRNAs harboring conserved terminal loops. Mol Cell 2008, 32:383-393

33. Cai $\mathrm{X}$, Hagedorn $\mathrm{CH}$, Cullen BR: Human microRNAs are processed from capped, polyadenylated transcripts that can also function as mRNAs. RNA 2004, 10:1957-1966

34. Jevnaker AM, Khuu C, Kjole E, Bryne M, Osmundsen H: Expression of members of the miRNA17-92 cluster during development and in carcinogenesis. J Cell Physiol 2011, 226:2257-2266

35. Wienholds E, Kloosterman WP, Miska E, Alvarez-Saavedra E, Berezikov E, de Bruijn E, Horvitz HR, Kauppinen S, Plasterk RH: MicroRNA expression in zebrafish embryonic development. Science 2005, 309:310-311

36. Mantovani R, Li XY, Pessara U, Hooft van Huisjduijnen R, Benoist C, Mathis D: Dominant negative analogs of NF-YA. J Biol Chem 1994, 269:20340-20346

37. Blanchette M, Kent WJ, Riemer C, Elnitski L, Smit AF, Roskin KM, Baertsch R, Rosenbloom K, Clawson H, Green ED, Haussler D, Miller W: Aligning multiple genomic sequences with the threaded blockset aligner. Genome Res 2004, 14:708-715

38. Wang Z, Zang C, Rosenfeld JA, Schones DE, Barski A, Cuddapah S, Cui K, Roh TY, Peng W, Zhang MQ, Zhao K: Combinatorial patterns of histone acetylations and methylations in the human genome. Nat Genet 2008, 40:897-903

39. Euskirchen GM, Rozowsky JS, Wei CL, Lee WH, Zhang ZD, Hartman S, Emanuelsson O, Stolc V, Weissman S, Gerstein MB, Ruan Y, Snyder M: Mapping of transcription factor binding regions in mammalian cells by ChIP: comparison of array- and sequencing-based technologies. Genome Res 2007, 17:898-909

40. Maerkl SJ, Quake SR: A systems approach to measuring the binding energy landscapes of transcription factors. Science 2007, 315:233237

41. Hooker CW, Hurlin PJ: Of Myc and Mnt. J Cell Sci 2006, 119:208-216

42. Guil S, Caceres JF: The multifunctional RNA-binding protein hnRNP A1 is required for processing of miR-18a. Nat Struct Mol Biol 2007, 14:591-596
43. Cawley S, Bekiranov S, Ng HH, Kapranov P, Sekinger EA, Kampa D, Piccolboni A, Sementchenko V, Cheng J, Williams AJ, Wheeler R, Wong B, Drenkow J, Yamanaka M, Patel S, Brubaker S, Tammana H, Helt G, Struhl K, Gingeras TR: Unbiased mapping of transcription factor binding sites along human chromosomes 21 and 22 points to widespread regulation of noncoding RNAs. Cell 2004, 116:499-509

44. Wierstra I: Sp1: emerging roles-beyond constitutive activation of TATA-less housekeeping genes. Biochem Biophys Res Commun 2008, 372:1-13

45. Ting AH, McGarvey KM, Baylin SB: The cancer epigenomecomponents and functional correlates. Genes Dev 2006, 20:32153231

46. Lennartsson A, Ekwall K: Histone modification patterns and epigenetic codes. Biochim Biophys Acta 2009, 1790:863-868

47. Jones PA, Baylin SB: The epigenomics of cancer. Cell 2007, 128: 683-692

48. Agalioti $\mathrm{T}$, Chen $\mathrm{G}$, Thanos $\mathrm{D}$ : Deciphering the transcriptional histone acetylation code for a human gene. Cell 2002, 111:381-392

49. Klein U, Tu Y, Stolovitzky GA, Keller JL, Haddad J Jr, Miljkovic V, Cattoretti G, Califano A, Dalla-Favera R: Transcriptional analysis of the B cell germinal center reaction. Proc Natl Acad Sci USA 2003, 100:2639-2644

50. Shaffer AL, Rosenwald A, Hurt EM, Giltnane JM, Lam LT, Pickeral OK, Staudt LM: Signatures of the immune response. Immunity 2001, 15: 375-385

51. Ci W, Polo JM, Cerchietti L, Shaknovich R, Wang L, Yang SN, Ye K, Farinha P, Horsman DE, Gascoyne RD, Elemento O, Melnick A: The BCL6 transcriptional program features repression of multiple oncogenes in primary B cells and is deregulated in DLBCL. Blood 2009, 113:5536-5548

52. Fu Y, Sinha M, Peterson CL, Weng Z: The insulator binding protein CTCF positions 20 nucleosomes around its binding sites across the human genome. PLoS Genet 2008, 4:e1000138

53. Phillips JE, Corces VG: CTCF: master weaver of the genome. Cell 2009, 137:1194-1211

54. Guccione E, Martinato F, Finocchiaro G, Luzi L, Tizzoni L, Dall' Olio V Zardo G, Nervi C, Bernard L, Amati B: Myc-binding-site recognition in the human genome is determined by chromatin context. Nat Cell Biol 2006, 8:764-770

55. Teye K, Okamoto K, Tanaka Y, Umata T, Ohnuma M, Moroi M, Kimura $\mathrm{H}$, Tsuneoka M: Expression of the TAF4b gene is induced by MYC through a non-canonical, but not canonical, E-box which contributes to its specific response to MYC. Int J Oncol 2008, 33:1271-1280

56. Meroni G, Reymond A, Alcalay M, Borsani G, Tanigami A, Tonlorenzi R, Lo Nigro C, Messali S, Zollo M, Ledbetter DH, Brent R, Ballabio A, Carrozzo R: Rox, a novel bHLHZip protein expressed in quiescent cells that heterodimerizes with Max, binds a non-canonical $\mathrm{E}$ box and acts as a transcriptional repressor. EMBO J 1997, 16:2892-2906 